\title{
Gestão Estratégica em Incubadora Tecnológica de Cooperativas Populares da Universidade Federal Da Paraíba - UFPB, Campus III, Bananeiras - PB
}

\author{
Strategic Management in Technology Incubator of Popular Cooperatives at the Federal \\ University of Paraíba - ufpb, Campus III, Bananeiras-PB
}

\begin{abstract}
Resumo
Este trabalho tem como objetivo compreender os elementos que compõem o processo de gestão estratégica em incubadora Tecnológica de Cooperativas Populares da Universidade Federal da Paraíba (UFPB), campus III, Bananeiras - PB. Portanto, a metodologia constou de duas etapas principais. A primeira etapa constituiu-se em uma pesquisa e revisão bibliográfica. Na segunda etapa foi feita uma pesquisa de campo, que forneceram dados para a verificação do tema proposto. Pode-se dizer que os fatores que causam a maioria dos problemas estratégicas da INCEPS são: grande dependência de terceiros, falta de recursos humanos capacitados, comprometimento e proativas, falta de apoio dos níveis hierárquicos superiores da UFPB, comprometendo assim o planejamento da Incubadora. Portanto, é importante considerar que cada organização deve definir sua estratégia de atuação, no caso do presente trabalho o planejamento estratégico deve ter a participação de todos os colaboradores ou pelo menos os que compõe o GT de Gestão da INCEPS.
\end{abstract}

Palavras-chave: Estratégia. Autogestão. Incubadora. Economia Solidária.

\begin{abstract}
This work aims to understand the elements that make up the process of strategic management in Technological incubator of popular cooperatives of the Federal University of Paraiba (UFPB), campus III, banana-PB. Therefore, the methodology consisted of two main steps. The first step consisted in a survey and literature review. In the second step was made a field research, which provided data for the verification of the proposed theme. It can be said that the factors that cause the most problems are: INCEPS great strategic dependence on third parties, lack of trained human resources, commitment and proactive, lack of support of the higher hierarchical levels of UFPB, undermining thus the planning of the incubator. Therefore, it is important to consider that each organization should define its operational strategy, in the case of this strategic planning work must have the participation of all employees or at least those who compose the GT INCEPS management.
\end{abstract}

Keywords: Strategy. Self-management. Incubator. Solidarity Economy.

Recebido: 02/11/2016 Aceito: 17/01/2017

Elenice da Silva Moraes ${ }^{1}$, José Mancinelli Lêdo do Nascimento ${ }^{2}$ e Telma Lúcia de Andrade Lima ${ }^{3}$

${ }^{1}$ Universidade Rural Federal de Pernambuco, Mestranda pelo Programa de Pós-graduação em Administração e Desenvolvimento Rural - elenicemoraes7@gmail.com - Rua Dom Manoel de Medeiros, S/N. Campus Dois Irmãos, Recife - PE, CEP: 52171-900

2 Universidade Federal de Campina Grande - UFCG, Doutor em Recursos Naturais - jm-ledo@uol.com.br

${ }_{3}^{3}$ Universidade Federal de Pernambuco, Doutora em Engenharia de Produção - tlima.ufrpe@gmail.com

\section{Introdução}


desenvolvimento da economia mundial vem sendo fortemente influenciada pela consolidação de um novo paradigma técnico-econômico, no qual a globalização da economia leva ao setor produtivo a um esforço crescente pela competitividade. (RIBEIRO et al, 2005). A nação que não domina ou não participa dos processos de inovação tecnológica está destinada à estagnação e à dependência. Investir no trinômio ciência-tecnologia-inovação é essencial para a sobrevivência das empresas e para o próprio futuro do país. (ZOUAIN e SILVEIRA, 2006).

A gestão estratégica é um processo gerencial, sistemático e contínuo que visa assegurar à empresa direção e continuidade das suas atividades a longo prazo, flexibilidade e agilidade no cotidiano organizacional. Em outras palavras, a gestão estratégica, trata-se de um método de prever e analisar o futuro de forma que a previsão futura seja bem planejada para o sucesso nos negócios. (TEIXEIRA et al, 2010).

Diante disso, as incubadoras universitárias são grandes incentivadoras em inovação tecnológicas e estratégia, apesar de serem recentes no Brasil, tendo crescimento relevante na década de 1990, surge com o objetivo específico na área empresarial: apoiar projetos organizados por empreendedores que se encontra em condições precária na sociedade. Por isso, a cooperação preside as relações, cria-se um ambiente tolerante e igualitário, tornando possíveis processos de recuperação de economias abaladas. (MYRDAL, 2000, apud, ARROYO, 2006).

Nesse contexto, destaca-se a importância das incubadoras de empreendimentos de economia solidária na discussão de uma alternativa ao desemprego. Assim, a economia solidária representa uma solução prática, que espontaneamente vem crescendo no Brasil e no mundo para superar tais problemas. Ela visa restabelecer o nível de ocupação pela organização e iniciativas dos excluídos, viabilizando sua reinserção na produção, via cooperativas e empresa solidárias. Entretanto, essas alternativas precisam de apoio.

Em face do quadro desfavorável no âmbito econômico e social, as incubadoras têm como desafio propor alternativas de ocupação e geração de renda que garantam sustentabilidade tanto do ponto de vista econômico, social, como também ambiental. Diante de tal perspectiva, se faz presente a forma de privilegiar a inserção no mercado de trabalho, possibilitando a gestão estratégica nas incubadoras de forma autônomas e voltadas para a consolidação da importância das formas coletivas de propriedade e dos laços de solidariedade entre os trabalhadores.

A primeira condição que conduz a realização desta pesquisa, refere-se a alta taxa de mortalidade das micro e pequenas empresas nos primeiros anos de existência. Isto se deve as condições do mercado financeiro possuir uma tímida fonte de investimentos, que é representada por altas taxas de juros, dificultando aos pequenos empreendimentos a sobreviverem no mercado competitivo. (FERREIRA et al, 2008).

Com o intuído de entender os procedimentos estratégicos de uma incubadora tecnológica de cooperativas populares, este trabalho tem o objetivo de compreender os elementos que compõem o processo de gestão estratégica em incubadora Tecnológica de Cooperativas Populares da Universidade Federal da Paraíba (UFPB), Campus III, Bananeiras - PB. Para responder tal objetivo, faz-se necessário responder o seguinte questionamento: Quais os elementos que compõem o processo de gestão estratégica em uma Incubadora Tecnológica de Cooperativas Populares?

\section{Referencial Teórico}

\subsection{Gestão estratégica}

Às micro e pequenas empresas, nem sempre estão preparadas para os efeitos da globalização, no qual a baixa intensidade de capital, falta de financiamento, precariedade da função gerencial, baixa qualificação de recursos humanos, precariedade da função tecnológica, falta de planejamento a longo prazo, e pequeno poder de barganha com parceiros comerciais, enfraquecem o empreendimento no mercado. (RAUPP e BEUREN, 2011).

A gestão estratégica surgiu para superar uma das principais limitações proporcionados pelo planejamento estratégico: o de sua implementação. As causas apresentadas para essa ocorrência, foi a dissociação da realidade organizacional apresentada no plano. Ou seja, com a elaboração do planejamento por consultores externos isentava a responsabilidade dos executivos de implanta-la na organização, levando o fracasso do planejamento estratégico. (TAVARES, 2010).

A gestão estratégica vem juntar o plano estratégico e implementação em um único processo, o qual visa as mudanças organizacionais necessárias para os 
responsáveis de executar e implantar os vários níveis organizacionais em seu processo decisório. O plano corresponde ao conjunto de atividades intencionais e planejadas de forma estratégica, operacionais e organizacionais, o qual agrega a capacidade interna da organização ao ambiente externo. (TAVARES, 2010).

A estratégia é um conjunto integrado e coordenado de compromissos e ações definido para explorar competências essenciais e obter vantagem competitiva. Quando definem uma estratégia, as empresas escolhem alternativas para competir. (HITT et al, 2012). Uma análise estratégica de uma organização, seja ela uma empresa ou uma incubadora, deve incluir um misto de racionalidade e subjetividade, seguindo um processo básico, que pode ajudar os administradores do negócio a entender melhor sua situação atual e quais são as melhores alternativas, ou meios, para se atingir os objetivos e as metas estipuladas. (DORNELAS, 2002).

\subsection{Modelo de Desenvolvimento e Implementação da Gestão Estratégica}

O processo de administração estratégica se se desenvolve em 4 fases, apresentadas na Figura 1, na qual o desenvolvimento em fases, mostrado na Figura 1. No qual o desenvolvimento e implementação da gestão estratégica é vista primeiramente no planejamento financeiro básico, seguida do planejamento baseado em previsões, planejamento orientado externamente e o planejamento estratégico. Deve-se compreender que este desenvolvimento para ser eficiente e eficaz em qualquer organização é uma tarefa duradoura e difícil, que exige apoio, concentração de esforços e muita paciência. (CERTO; PETER, 2010).

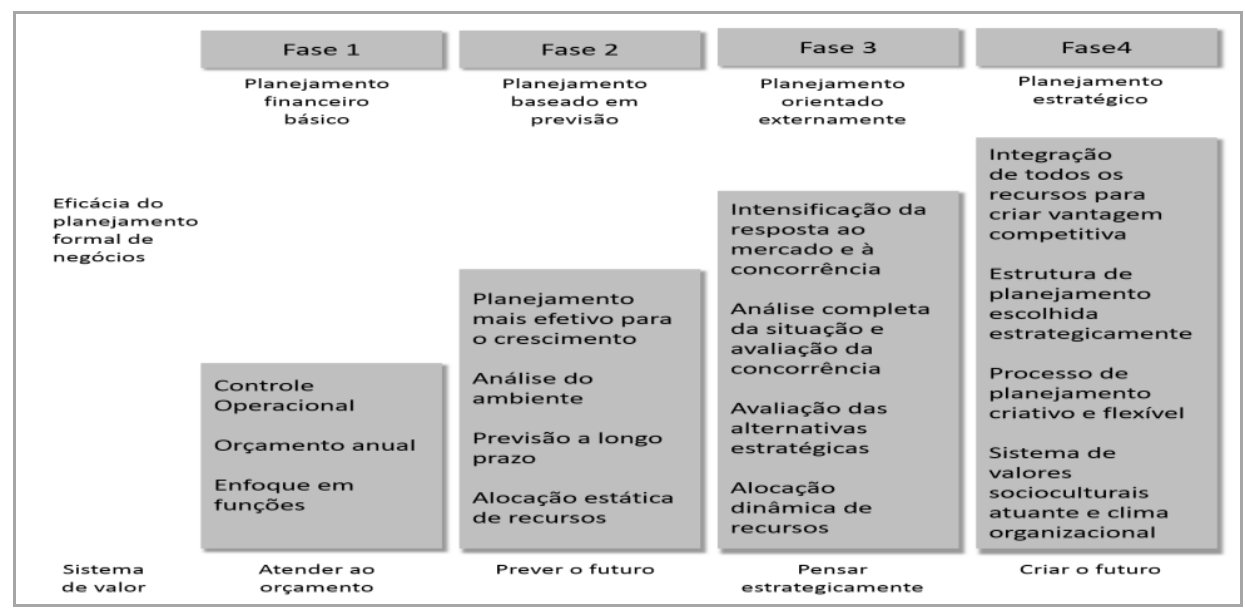

Figura 1: Fase do Desenvolvimento e Implementação da Gestão Estratégica

Fonte: Gluck et al, (1980), apud Certo, Peter (2010, p.19).

De acordo com a Figura 1, as fases servem de norteamento para cada etapa dos processos de desenvolvimento e implementação, iniciando-se com o controle do fluxo de caixa e planejamento financeiro anual, seguido do objetivo, o qual reduz a diferença entre as metas e os resultados, controlando a disponibilidade de recursos. A organização passa a analisar sua posição frente as ameaças. Rever seu portfólio de produtos, agregar valor ou não a eles, pois a organização é direcionada pela inovação, adquire habilidades para responder às mudanças de mercado. Outro fator de grande importância é o diagnóstico, pois um erro nesta fase prejudicará todo $\mathrm{o}$ resto do processo de desenvolvimento $\mathrm{e}$ implementação do planejamento estratégico.

\subsubsection{Planejamento Estratégico}

Segundo Oliveira (2014), existe três tipos de planejamentos, os quais são levados em consideração aos grandes níveis hierárquicos:

- Planejamento estratégico;

- Planejamento tático;

- Planejamento operacional.

Diante disso, esses três níveis de planejamento podem ser relacionados a decisão de uma pirâmide organizacional, conforme mostra a figura 2 . 


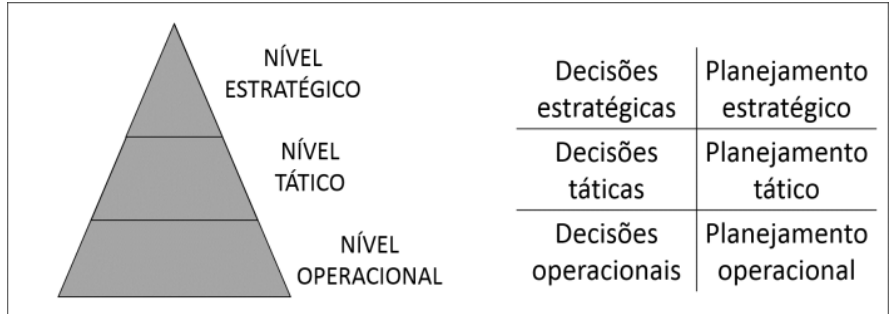

Figura 2: Níveis de decisão e tipos de planejamento

Fonte: Oliveira (2014, p.15).

Segundo Oliveira (2014, p.17), “planejamento estratégico é o processo administrativo que proporciona sustentação metodológica para se estabelecer a melhor direção a ser seguida pela empresa". Ou seja, o planejamento deve conter fatores externos que estejam estruturados de forma inovadora e diferenciada das demais organizações para a sobrevivência no mercado competitivo.

O "planejamento tático é a metodologia administrativa que tem por finalidades otimizar determinada área de resultado e não a empresa como um todo". Trabalha com os níveis meios da organizacionais, ou seja, tendo como principal finalidade a decomposição dos objetivos, estratégias e políticas estabelecidas no planejamento estratégico. (OLIVEIRA, 2014, p.19). A Figura 3 apresenta uma sistemática de desenvolvimento dos planejamentos táticos.

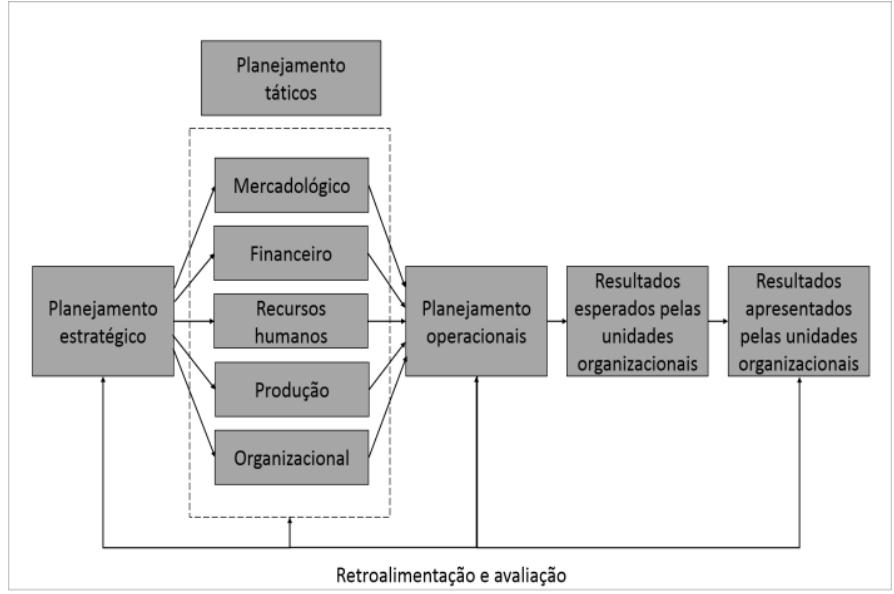

Figura 3: Desenvolvimento de planejamento tático Fonte: Oliveira (2014, p.19).

Segundo Oliveira (2014, p.19), o "planejamento operacional é a formalização, principalmente através de documentos escritos, das metodologias de desenvolvimento e implantação de resultados específicos a serem alcançados pelas áreas funcionais da empresa". Nesta operação corresponde os planos de ação ou planos operacionais. Para isto, o planejamento operacional deve conter, com detalhe, os seguintes requisitos:

- Recursos necessários para seu desenvolvimento e implantação;

- Procedimentos básicos a serem adotados;

- Resultados finais esperados;

- Prazos estabelecidos; e

- Responsáveis por sua execução e implantação.

O planejamento operacional está preocupado com as atividades ligadas ao dia-a-dia da empresa, por isso, a elaboração dos planos para a execução das rotinas são de suma importância para as organizações, independentemente do tamanho de sua estrutura.

\subsubsection{Missão da Organização}

Segundo Hitt et al, (2012, p.18), a missão da empresa é mais concreta que a visão. Porém a missão deve conter individualidade como a visão, pois deve ser inspiradora e relevante para todos os stakeholders. Diante disto, "a missão especifica o negócio no qual a empresa pretende competir e os clientes aos quais pretende atender".

O propósito da missão corresponde aos compromissos que a empresa tem para cumpri-la, pois ela atua ou está analisando a possibilidade de entrada no setor, mesmo que a situação esteja em possibilidade reduzida. (OLIVEIRA, 2014). A definição da missão deve corresponder com alguns critérios:

- Suficientemente empreendedores para terem impacto sobre o comportamento da empresa;

- Mais focados no sentido da satisfação das necessidades dos clientes do que nas características dos produtos ou serviços oferecidos ao mercado;

- Capazes de refletir as habilidades essenciais da empresa;

- Entendíveis;

- Realistas;

- Flexíveis; e

- Motivadores.

Os fatores para a formulação da missão é a postura estratégica, o qual corresponde a maneira ou postura mais adequada para alcançar o propósito da missão. Porém, os executivos devem estabelecer a macro estratégia, na qual estão as grandes ações ou caminhos para usufruir e gerar vantagens 
competitivas no ambiente. E a macro política que correspondem as grandes orientações que servirá de base para a tomada de decisões, que as organizações devem interagir com o ambiente. (OLIVEIRA, 2014).

\subsubsection{Controle e Avaliação}

O controle e a avaliação no processo de planejamento estratégico é acompanhar o desempenho do sistema, no cumprimento dos objetivos, desafios e metas, bem como da avaliação das estratégias e políticas seguida pela empresa. O controle é o processo administrativo que mediante aos padrões previamente estabelecidos, procura medir e avaliar o desempenho e o resultado das ações, no qual servirá de norteamento na execução do planejamento. (OLIVEIRA, 2014). Para atender tais perspectivas, deve-se seguir algumas fases:

- Estabelecimento de padrões de medida e avaliação: esses padrões são decorrentes dos objetivos, desafios, metas, estratégias, políticas e projetos, bem como das normas e procedimentos.

- Medidas dos desempenhos apresentados: é o processo de medir e avaliar desempenho, significa estabelecer o que medir e selecionar, utilizando critérios de quantidade, qualidade e tempo.

- Comparação do realizado com o resultado esperado: o resultado dessa comparação servirá de norteamento para os executivos, ou seja, se o desvio apresentado estiver dentro do esperado, o executivo não deve preocupar-se, porém se o desvio exceder um pouco do esperado, o executivo deverá continuar sua ação, mas com alguns ajustes. Se o desvio exceder muito ao que foi planejado, o executivo deverá interromper suas ações até que as causas sejam explicadas.

- Ação corretiva: corresponde as medidas ou providências que são adotadas para eliminar os desvios significativos que o executivo detectou, ou seja, focar nos pontos críticos, está bem explicado e detalhado, rígidos e preciso, realista e operacionalizável, apresentar um custo menor que os benefícios, ser ágil e proporcionar medidas de correção de maneira rápida, e ter objetividade.

\subsubsection{Estruturação Organizacional}

As estratégias organizacionais são formuladas pela alta direção para alcançar os objetivos globais da empresa. Elaborar e estabelecer estratégias gerais, e definir e decidir o papel das diversas linhas de negócios da organização e quais recursos serão alocados. (CERTO; PETER, 2010). Para atingir tal estrutura organizacional, o executivo deve prestar atenção nos modelos estabelecidos pela a empresa.

A figura dos componentes, condicionantes, níveis de influência e níveis de abrangência da estrutura organizacional, representa bem a organização e o método em que os analistas de sistemas devem ter, pois a consciência da estrutura organizacional é o básico para o desenvolvimento de todos os outros trabalhos dentro da organização.

Dentre vários fatores, as organizações devem se preocupar com o sistema de responsabilidade, o qual refere-se à obrigação que a organização tem com colaboradores, clientes e fornecedores. Os aspectos da responsabilidade da organização é a departamentalização, linha e assessoria e atribuições das unidades organizacionais. (Oliveira, 2002).

A departamentalização é a forma em que a organização está estruturada e subdividida, pois é nela que se encontra os recursos humanos, financeiros, matérias e equipamentos nas organizações. Nos quais está formulado em várias formas de departamentalização, entre estas estão por qualidade, funcional, territorial, produto/serviço, clientes, processo, projeto, matricial e mista.

As Unidades Estratégica de Negócio - UEN é a unidade ou divisão da empresa, o qual é responsável para o desenvolvimento de várias áreas estratégica de negócios - AEN. Segundo Oliveira (2002), esta unidade é estruturada para obtenção de resultados organizacionais, entre eles estão:

- Incremento do faturamento;

- Otimização de utilização dos vários recursos existentes;

- Ter melhor interação com as oportunidades de mercado;

- Auxiliar na operacionalização do plano tributário;

- Desenvolver o nível de qualidade das atividades;

- Ter um saudável clima competitivo interno; e

- Ter uma situação otimizada de sinergia empresarial.

\subsection{Aspectos Históricos das incubadoras}

O termo incubadora foi criado no século $\mathrm{XX}$, no final da década de 1950, quando uma das maiores 
indústrias do estado de Nova Iorque fechou as portas, como consequência imediata da proliferação dos parques tecnológicos nos Estados Unidos, daí surge a Batavia Industrial Center, fundada em 1959, conhecida com a primeira incubadora dos Estados unidos. No Brasil, a primeira incubadora de empresas surgiu muito tempo depois, em 1985, na cidade de São Carlos - São Paulo. (DORNELAS, 2002; GONÇALVES e FREIRE, 2007; SPERANCINI et al, 2013).

As incubadoras de empresas são parte substancial dos sistemas locais de inovação tecnológica, pois permitem a transferência de tecnologia entre a universidade e o setor produtivo. Por isso, o modelo de gestão estratégico para incubadora se faz necessário para $\mathrm{o}$ desenvolvimento eficaz das empresas incubadas, as quais ajudam na criação de novas empresas sólidas, especialmente porque as empresas iniciantes enfrentam problemas, como a falta de capital fixo, inexperiência em gestão e conhecimento de mercado. (SILVA e ANDRADE JÚNIOR, 2012).

O modelo configura-se em temas estratégicos amplos, direcionados a objetivos estratégicos específicos. Em outras palavras, cada tema estratégico é subdivido em processos, e estes representam o menor conjunto de atividades e ações estratégicas que necessitam ser executadas em determinado período de tempo e velocidade. Para facilitar a compreensão, pensemos no tema estratégico comunicação. (COELHO JÚNIOR, 2003).

Diante disso, as incubadoras apresentam um importante papel socioeconômico já que conseguem, na maioria das vezes, reunir em um ambiente auxílio na aquisição de financiamentos, apoio administrativo e de estrutura. Além, do auxílio de gerência, financiamento e serviços de sustentação técnica. Não se aplica só na criação de empresas, mas também o monitoramento para estimular o processo de inovação. $\mathrm{O}$ principal objetivo deve ser a produção de empresas de sucesso, mesmo após deixarem a incubadora, geralmente em um prazo de três a quatro anos. (RAUPP e BEUREN, 2011).

Nas incubadoras universitárias, os professores, técnicos e acadêmicos se organizam para pôr em prática outras formas de organizar o trabalho, valorizam e estimulam o diálogo com os trabalhadores interessados em organizar os seus empreendimentos, enfim, participam como educadores e como pessoas que precisam aprender com as outras.
Além disso, as experiências de incubação enriquecem e modificam a forma de ensinar, pesquisar e desenvolver ações de extensão universitária, promovendo a multidisciplinaridade, indispensáveis nesse trabalho coletivo. Ou seja, potencializa a integração entre ensino, pesquisa e extensão, o que viabiliza a transferência de conhecimentos e tecnologias para as comunidades que participam de programas de incubação de empreendimentos de economia solidária.

Os trabalhadores que participam de empreendimentos solidários, por sua vez, viabilizam a criação de trabalho e renda, mudam sua forma de pensar e agir e, assim, aumentam a sua autoestima, se sentindo mais respeitados, fortes e imponderados para interagir na comunidade onde vivem.

Ao adquirirem o status de cooperados ou associados em um empreendimento desse tipo, com autonomia para exercer a autogestão, esses trabalhadores ganham visibilidade, respeito dentro e fora de suas comunidades, conquistam a sua cidadania, e têm acesso a conhecimentos e tecnologias que as universidades, por meio de seus professores, pesquisadores, técnicos e acadêmicos, podem dispor.

Todas essas dimensões precisam ser trabalhadas e superadas. Por isso, a importância das incubadoras universitárias possuírem em suas equipes pessoas de diversas áreas do conhecimento, desde aquelas voltadas para as técnicas organizacionais e de negócios (como saúde, psicologia, educação, direito e recursos humanos) entre outras que podem trabalhar as questões de conflito, de conhecimento e reconhecimento de cada um em benefício do relacionamento no interior dos empreendimentos.

A participação das incubadoras universitárias de empreendimentos de economia solidária, embora ainda seja um processo em construção, resultou em grandes avanços nos aspectos políticos, educacionais, da formação empreendedora, da organização empresarial, da produção e da comercialização solidária; mas há ainda muitos desafios a serem vencidos e longos caminhos a serem percorridos.

O Sistema de Cooperativas Solidárias está presente em todos os Estados da Nação, articulando 1.200 Cooperativas, presentes em diversos ramos cooperativos. Estes ramos cooperativos possuem formatos e regras diferentes de organização, orientadas pelas instâncias legais, comerciais ou financeiras a que são vinculadas (ZANCO, 2016). 


\subsubsection{Gestão estratégica para incubadoras}

Segundo Zouain e Silveira (2006, p.3), “a questãochave para se definir um modelo de gestão é o entendimento sobre as características do objeto de estudo, seus principais processos, suas competências centrais, suas relações com os agentes externos que influenciam seu desempenho e sua estratégia de atuação". Por isso, dentre os elementos do macroprocesso das incubadoras, destaca-se a residências, principal macroprocesso das incubadoras é o de residência, ou seja, vê o surgimento de novas empresas, pois sendo o principal o principal objetivo dos programas de incubação. De maneira geral, as incubadoras buscam aumentar a eficiência do processo de incubação através da melhoria da qualidade dos candidatos, aumento da eficiência do período de residência, e pelo aumento das chances de sobrevivência das empresas graduadas.

Diante disso, os processos das incubadoras de empresas devem ser definidos para que se alcance maior eficiência nos resultados por elas estabelecidos. Considerando o que foi apresentado a Figura 4 mostra bem esses processos.

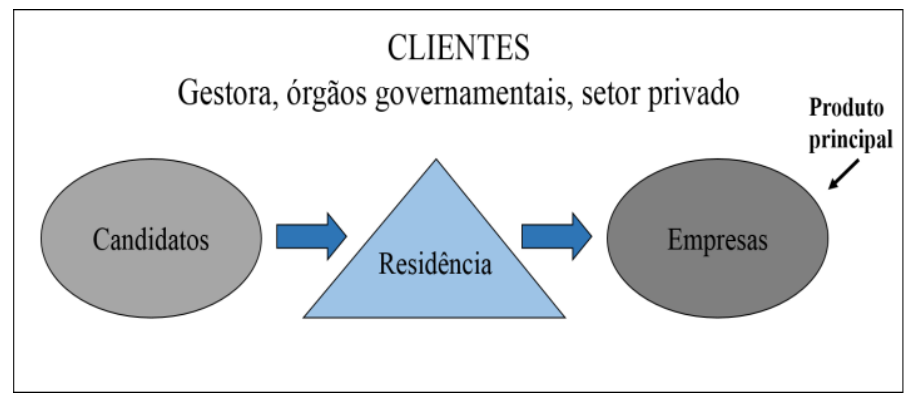

Figura4: Macroprocesso principal dos programas de incubação Fonte: Caulliraux (2001, p.11)

Da inter-relação entre candidatos, residência e a formação de empresas, deve-se incluir adequadamente um conjunto de indicadores para o processo de avaliação do progresso de implementação das estratégias é uma atividade vital para o sucesso do processo. O sistema de indicadores da entidade gestora deve medir o grau de adesão aos fundamentos estratégicos da instituição gestora. No módulo de planejamento estratégico, são identificados apenas os indicadores da organização, para que sua medição seja realizada no módulo de controle. (ZOUAIN e SILVEIRA, 2006). Diante disso, são apresentados alguns indicadores de desempenho sugeridos pelo Comitê Gestor do Programa Nacional de Apoio às Incubadoras de Empresas:
- Indicadores de pré-incubação - número total de projetos na pré-incubação, números de projetos incubados resultantes da pré-incubação, número de projetos em pré-incubação que se tornaram empresas sem passar por incubadoras, número de alunos envolvidos em projetos na fase de pré-incubação total de alunos matriculados em programas de empreendedorismo e o número de projetos em préincubação originados de pesquisa desenvolvida em centros tecnológicos;

- Indicadores de incubação - número de projetos selecionados para incubação/número total de candidatos à incubação, total de faturamento nos últimos 12 meses das empresas residentes/número total de empresas residentes, total de faturamento nos últimos 12 meses das empresas residentes/número total de colaboradores das empresas residentes, número de rescisões contratuais/número total de empresas graduadas, número de módulos ocupados/número total de módulos disponíveis, número de empresas graduadas/número de empresas incubadas, número total de produtos (serviços) gerados pelas empresas incubadas/número de empresas incubadas, tempo de incubação (meses) das empresas graduadas/número total de empresas graduadas, total de custos operacionais/total de receitas próprias, total de faturamento nos últimos 12 meses das empresas residentes/total de faturamento das empresas residentes no período anterior, número de empresas certificadas (ISO, PNQ etc.)/número de empresas incubadas e o número total de empresas graduadas estabelecidas no mercado/número total de empresas graduadas;

- Indicadores de pós-incubação - número de empresas graduadas com vínculo formal com instituições de pesquisa/número total de empresas graduadas, número de empresas graduadas instaladas em parques tecnológicos/número total de empresas graduadas, total de faturamento nos últimos 12 meses das empresas graduadas/número total de empresas graduadas e o total de faturamento nos últimos 12 meses das empresas graduadas/número total de colaboradores das empresas graduadas;

Para definir o planejamento da incubadora deve-se representar a definição dos objetivos, do plano de metas e das estratégias operacionais vinculadas ao processo de negócio da entidade executora. Segundo Zouain e Silveira (2006), para executar um planejamento de forma eficaz, deve-se utilizar a sequência de seis passos: 
- Passo 1 - alinhar percepções quanto ao futuro;

- Passo 2 - mapear os processos;

- Passo 3 - definir missão e visão;

- Passo 4-definir os objetivos e metas;

- Passo 5 - formular a estratégia da entidade executora; $\mathrm{e}$

- Passo 6 - definir indicadores de desempenho operacionais.

As incubadoras de tecnologia de cooperativas populares adotam a Economia Solidária - ES, como perspectivas de autogestão. No qual, a Economia Solidária muitas vezes é utilizada com diferentes significados, onde apresenta um princípio básico, invariável, que se reporta à ideia de solidariedade em contraste com o individualismo que caracteriza a economia capitalista. Este conceito já é amplamente usado no Brasil e em diversos países.

Os empreendimentos econômicos solidários se apresentam como organizações voltadas para a produção tanto em áreas urbanas como rurais, baseados na livre associação, no trabalho cooperativo, na autogestão e no processo decisório democrático. Havendo diversas formas sob as quais a economia solidária possa se manifestar, a cooperativa representa a sua forma clássica e a que mais cresce.

Com essa nova forma de empreendimentos de economia solidária que se desenvolve no século XXI tem o cooperativismo operário como principal antecedente, o qual surgiu durante o século XIX em reação à Revolução Industrial, uma tentativa de construir outra maneira de organizar a economia, com base no trabalho associado e na distribuição equitativa do excedente adquirido e não na acumulação individual do dinheiro a partir da exploração do trabalho alheio.

Para Singer (2002), a definição da economia solidária está ligada à relação entre o trabalhador e os meios de produção, uma vez que a empresa solidária nega a separação entre trabalho e posse dos meios de produção, usada na base do capitalismo. A empresa solidária é formada basicamente de trabalhadores, que secundariamente são seus proprietários. Por isso, sua finalidade básica não é maximizar lucro, mas a quantidade e a qualidade do trabalho.

Esse processo visa, fundamentalmente, valorizar o saber acumulado das pessoas e do grupo no campo da produção com vistas à inclusão social e econômica, acrescentando conhecimentos técnicos à organização cooperativista e técnicas específicas de produção e gestão administrativa. Trata-se, portanto, de unir o "saber popular" ao "saber científico" numa tentativa de transformar a prática cotidiana de produção e comercialização através das atividades de ensino, pesquisa e extensão.

Além disso, esse processo educativo modifica as circunstâncias da produção ao introduzir mudanças tecnológicas, mas também contribui para integrar homens e mulheres na sua maneira de ser e agir. Assim, trata-se de um processo de construção e reconstrução dos conhecimentos vindos da Academia para os atores envolvidos nos empreendimentos solidários.

\section{Procedimentos metodológicos}

O procedimento da metodologia da pesquisa é o estudo dos métodos em um determinado processo, tem como objetivo captar e analisar os dados coletados na pesquisa. A investigação científica segundo Gil (2008, p. 8) está relacionada a um "conjunto de procedimentos intelectuais e técnicos", ou seja, os métodos utilizados devem estar de forma clara e objetiva, pois assim garantirá sucesso na coleta dos dados.

\subsection{Caracterização da Pesquisa}

A pesquisa tem por finalidade delinear a forma como foi desenvolvida, englobando os procedimentos metodológicos utilizados e a caracterização do objeto de estudo. Isto se faz necessário, visto que todo trabalho de cunho científico deve estar fundamentado em métodos para que seus objetivos sejam alcançados e seus resultados sejam aceitos pela comunidade acadêmica.

Segundo Lakatos e Marconi (2007), os métodos e as técnicas de pesquisa devem adequar-se ao problema a ser estudado, às hipóteses levantadas, ao tipo de informantes com os quais se vai trabalhar. Diante disso, o método escolhido depende do objeto da pesquisa, dos recursos financeiros, recursos humanos, e entre outros elementos da investigação.

Assim, para elaboração deste estudo foi utilizada abordagem qualitativa, que historicamente é utilizada em alguns campos específicos de investigação nas ciências sociais, podendo ser em estudos voltados ao setor público ou por falta de quantidade insuficiente a amostras quantitativas.

Do ponto de vista dos objetivos e considerando os critérios de classificação proposto por Vergara (2006), deve-se analisar os fins e os meios. Quanto 
aos fins: trata-se de uma pesquisa exploratória e descritiva, pois tem como objetivo proporcionar maior familiaridade com o problema, com vistas a torná-lo mais explícito ou a construir hipóteses, tem grande valor, pois serve de base a outros tipos de estudos. Quanto aos meios: trata-se de pesquisa, ao mesmo tempo, bibliográfica e de campo.

Segundo Gil (2002), as principais técnicas utilizadas em pesquisas para auxiliar os métodos, são os questionários, a entrevista, o formulário, a internet e os meios de comunicação de massa: rádio, TV, telefone e outros. Como técnica de levantamento de dados utilizou-se a entrevista informal com o coordenador da Incubadora que forneceu os dados que se necessita para a conclusão do trabalho.

Portanto, a metodologia da pesquisa consta em duas etapas principais. A primeira etapa constituiu-se em uma pesquisa e revisão bibliográfica, fornecendo elementos que serviram como base conceitual e instrumental para a etapa seguinte. Na segunda etapa foi feita uma pesquisa de campo, que forneceram dados para a verificação do tema proposto.

\subsection{Ambiente da Pesquisa/ Sujeito da Pesquisa}

O ambiente da pesquisa foi na INCEPS Incubadora de Empreendimentos Populares Solidários, localizada na Universidade Federal da Paraíba - UFPB, Campus III, Bananeiras - PB, microrregião do Brejo paraibano, que está representada por um professor coordenador, professores colaboradores, e alunos bolsistas e voluntários.

A pesquisa foi realizada na unidade de planejamento estratégico para incubadora da UFPB no município de Bananeiras, com a participação limitada de agentes envolvidos na pesquisa. $\mathrm{O}$ sujeito da pesquisa foi o coordenador da INCEPS, tal escolha, deve-se ao fato do mesmo ser o responsável pelo projeto e os demais participantes serem de livre adesão e rotatividade no projeto.

\subsection{Estratégia de coleta a tratamento dos dados}

Seguiu-se no procedimento das técnicas de pesquisa, realizando-se a pesquisa documental através de informações extraídas junto à Incubadora. A coleta de dados constitui uma etapa importante da pesquisa de campo.

Sendo assim, os dados levantados foram de natureza primária, pois para a coleta dos dados foi utilizada a entrevista aplicada ao coordenador da INCEPS, responsável pelo planejamento estratégico da Incubadora. Na presente pesquisa foi utilizada a entrevista semiestruturada. Nesse tipo de entrevista foram elaboradas questões abertas e fechadas, sendo utilizado um roteiro previamente determinado. E a entrevista informal ou não estruturada, que proporciona uma visão geral do problema pesquisado, quase uma conversa.

\section{Apresentação dos dados e discussão dos resultados}

Nesta seção é apresentado os resultados da pesquisa de campo, tendo como base de orientação os objetivos traçados. As informações foram apresentadas em subseções específicas, objetivando elucidar o sentido dos dados e das informações levantadas. Primeiramente, é apresentado uma breve caracterização do ambiente de pesquisa, ou seja, a INCEPS - Incubadora de Empreendimentos Populares Solidários da UFPB, Campus III, Bananeiras- PB. Ao mesmo tempo, apresenta-se uma breve caracterização do sujeito pesquisado, o coordenador da INCEPS, responsável pelo Planejamento Estratégico executado na Incubadora. $\mathrm{Na}$ sequência é realizada uma descrição da caracterização da Incubadora. Logo após, será realizada uma descrição das etapas dos princípios do planejamento estratégico da INCEPS. Por último, serão identificados os gargalos, isto é, as restrições e dificuldades existentes durante o processo de gestão estratégica da INCEPS.

\subsection{Caracterização do ambiente da pesquisa e do sujeito pesquisado}

A presente pesquisa foi realizada na INCEPS Incubadora de Empreendimentos Populares Solidários, Campus III, Bananeiras- PB. A INCEPS foi criada no ano de 2005 como um escritório local da INCUBES, incubadora do Campus I, João Pessoa-PB, e ficou independente em 2007, mudando seu nome para INCEPS. Porém, parou de funcionar em 2009 e voltou a funcionar em 2011, quando o Professor Genyson Marques Evangelista retornou do Doutorado, mas só se estruturou de forma organizada quando passou a recebe auxílio financeiro do PROEXT em 2015.

A Incubadora é considerada de médio porte, pois ela abrange a região do brejo e litoral da Paraíba. 
Tendo atividades predominantes na produção agropecuária e agroindústria alimentar, porém, a partir de março de 2016 iniciará a incubação de um novo empreendimento, uma cooperativa de resíduos sólidos.

Embora o quadro de professores seja de cinco professores (Genyson Marques Evangelista, Raíssa Dália Paulino, Jussara Ellen Morais Frazão, Raonira da Costa Araújo e Alda Lúcia de Lima Amâncio). Além dos professores, há um técnico administrativo, Edson Lindolfo, que também desenvolve a função de professor de avicultura. Quanto aos alunos, são oito bolsistas e um voluntário atualmente, com perspectiva de seleção de mais seis alunos voluntário ainda neste ano de 2016.

O principal objetivo da Incubadora é: Contribuir com o desenvolvimento da economia solidária no estado da Paraíba, seja criando novos empreendimentos solidários, seja aprimorando a gestão de empreendimentos já existentes.

A contribuição da Incubadora é relevante, sobretudo pelo o aperfeiçoamento de vários empreendimentos na região polarizada a Bananeiras $\mathrm{PB}$, como associações de piscicultores, cooperativas de agricultura orgânica e avicultura. A sua importância para a economia local reside em viabilizar os negócios dos grupos incubados, principalmente na colocação de seus produtos no mercado.

No que diz respeito à caracterização do pesquisado, trata-se do coordenador da INCEPS, Genyson Marques Evangelista, Mestre em Economia e Doutor em Sociologia, professor nas áreas de Economia e Sociologia pela Universidade Federal da Paraíba - UFPB, Campus III, Bananeiras - PB.

\subsection{Caracterização dos princípios do planejamento estratégico}

Esta seção do trabalho trata da caracterização do Planejamento Estratégico desenvolvido pela INCEPS. Desse modo, para realizar o levantamento das questões apresentadas nessa seção foi utilizado principalmente um roteiro com perguntas abertas que identificou características essenciais ao desenvolvimento da pesquisa, possibilitando uma melhor compreensão e para obtenção dos dados. Além disso, é importante salientar que durante a pesquisa foi possível realizar observações in loco que possibilitaram a confirmação dos dados e acesso a outras informações importantes ao estudo.
Sendo assim, como etapa inicial foi solicitado o acesso ao planejamento estratégico, junto a responsável de coordenar os projetos da INCEPS, para levantar informações a respeito da caracterização do mesmo. Para tanto, a pesquisadora teve acesso a cópia do planejamento estratégico via e-mail, porém constatou que não seria um planejamento estratégico propriamente dito. Diante disso, com o planejamento em mãos e as respostas da entrevista, foi possível de compará-las no diagnóstico final.

Quando perguntado ao coordenador da INCEPS sobre o processo da estratégia e tradução da estratégia em termos operacionais, no decorrer de formulação/ definição da estratégia (análise, concepção, seleção e direcionamento da estratégia), o Coordenador afirma que:

\section{A estratégia da Incubadora depende fundamentalmente das características de cada empreendimento. De um modo geral, ela envolve a escolha do empreendimento a partir da demanda espontânea dos grupos interessados e a utilização do planejamento participativo na definição do processo de incubação. (Coordenador).}

Porém, a estratégia descrita pelo Coordenador não explica de forma clara a estratégica dita por Oliveira (2014, p.187), na qual "a finalidade das estratégias é estabelecer quais serão os caminhos, os cursos, os programas de ação que devem ser seguidos para serem alcançados os objetivos, desafios e metas estabelecidas". A estratégia descrita mostra uma não conformidade com o planejamento a longo prazo, sendo identificado em um empreendimento especifico, mostrando ser um planejamento a curto prazo. Mostra que a Incubadora utiliza o planejamento operacional, o qual tem foco básico nas atividades do dia-a-dia da Incubadora.

Para tanto, foi perguntado ao Coordenador, como a Incubadora traduz e desdobra a estratégia, se utilizava alguma metodologia ou algum sistema de gestão. Se há o desdobramento da estratégia para os demais níveis em objetivos, metas, iniciativas e planos de ação. O acompanhamento/ monitoramento dos resultados definidos na estratégia. Se são utilizados indicadores na hora de medir seus objetivos, metas, iniciativas e planos de ação. Se caso fosse afirmativo, como seria esses indicadores, como foram definidos e quais são os tipos de indicadores utilizados (financeiros, não-financeiros). Se esses indicadores englobam os diferentes aspectos do negócio e são 
interligados, no intuito de demostrar se o resultado apresentado por um deles tem impacto aos demais. As respostas proferidas pelo Coordenador estão descritas a seguir.

No passado não existiu nenhuma metodologia, porém só agora que a Incubadora está passando por um processo de aprimoramento de sua gestão.

E está sendo utilizado um modelo de gestão. (Coordenador).

Só em termos de objetivos, metas e iniciativas, pois o plano de ação da INCEPS ainda está em processo de formulação. (Coordenador).

Sim, para todos os empreendimentos são utilizados indicadores. (Coordenador).

Os indicadores são tanto econômicos como técnicos. No caso desses últimos, pegando a piscicultura, por exemplo, definimos os seguintes indicadores: tempo de crescimento dos peixes, taxa de conversão alimentar e controle da qualidade da água, entre outros. (Coordenador).

Sim, pois todos os indicadores se influenciam mutuamente. Por exemplo, a relação preço da ração/ preço do produto na piscicultura e na avicultura, por exemplo, influencia enormemente o grau de eficiência produtiva na comercialização do produto. (Coordenador).

Mesmo constatado anteriormente, a Incubadora não possuí uma metodologia ou sistema de gestão, o Coordenador explica que esse processo está em andamento, o qual apresenta um modelo de gestão, porém não especifica qual modelo está sendo atotado pela Incubadora, levando em conta a metodologia do Planejamento Estratégico, o qual faz necessário em qualquer organização, seja ela pública ou privada, a definição em termos da empresa como um todo, "aonde se quer chegar" e depois se estabelece "como a empresa está para chegar na situação desejada". (OLIVEIRA, 2014, p.40).

Quanto ao desdobramento da estratégia, o Coordenador afirma que os objetivos, metas e iniciativas estão sendo cumprido pela Incubadora, porém o plano de ação ainda está sendo elaborado. Entretanto, o plano de ação preocupa-se com a concentração das especialidades de um projeto, ou seja, os recursos humanos, tecnologia, marketing, informática, logística, entre outros. Diante disso, o plano ação deve ser elaborado em conjunto aos projetos englobado aos empreendimentos.
Os indicadores permitem avaliação do desempenho da organização, "seguindo três aspectos relevantes: controle, comunicação e melhoria”. Além de "ser especificados por meio de métricas estatísticas, comumente formados por porcentagem, média, número bruto, proporção e índice". (MARTINS e MARINI, 2010, p.107). Diante disso, o Coordenador mostra ter controle sobre os indicadores utilizados pela Incubadora, utilizando meios econômicos e técnicos na mensuração dos resultados.

Sobre o alinhamento da organização à estratégia, foi perguntado se a Incubadora realiza alimento do negócio visando compartilhar processos em comum e criar sinergia para alcançar a estratégia. De acordo com o Coordenador, ainda não possuem nenhum alinhamento estratégico.

Quando questionado sobre a forma de transformar a estratégia em tarefa de todos os colaboradores, e se os mesmos compreendem a estratégia da Incubadora de forma clara e objetiva, o entrevistado afirma que:

Nem todos, principalmente os estudantes bolsistas que entraram recentemente no quadro da Incubadora e aqueles professores que ainda não se engajaram para valer nas suas atividades. (Coordenador).

Na visão do Coordenador, os alunos e professores que possuem pouca experiência na INCEPS, não compreendem bem as estratégias adotadas pela Incubadora. Isso deve-se pôr o modelo do planejamento não conter objetivos claros e consistente, pois, mesmo que um colaborador tenha passando pouco tempo na instituição o plano deve ser claro e objetivo para a compreensão do que está sendo executado.

Quando foi perguntado se a Incubador utiliza algum programa para comunicar a estratégia aos colaboradores e aos empreendimentos incubados o colaborador disse que sim. Caso fosse afirmativo o Coordenador deveria explicar como era realizado (jornais, newsletters, folhetos, treinamentos, facebook, WhatsApp, outros), a periodicidade de realização desses programas e a existência de algum critério de confidencialidade das informações.

Capacitação processual dos colaboradores, seja através de atividades de campo, seja na realização de debates e análise de textos, pelo 
facebook, whatsApp, e também comunicados na homepage da Incubadora. (Coordenador).

A periodicidade de realização desses programas é contínua, mas varia muito de acordo com a dinâmica de cada empreendimento. (Coordenador).

Ainda não possuímos confidencialidade das informações. (Coordenador).

Segundo Oliveira (2002), as condições do sistema de comunicações, é formada no processo mediante mensagem, enviada por um emissor através de determinado meios de comunicação. Isto, de acordo com o Coordenador da INCEPS ele funciona por vários meios de comunicação, dentre eles estão: atividades de campo, debates e análise de textos, como ferramentas nas redes sociais, como facebook, whatsapp e o site da Incubadora. Esse processo é de forma contínua, em que os colaboradores devem submeter, pois para atender os empreendimentos incubados a equipe deve estar bem preparada. Porém não possuem nenhuma ferramenta de confidencialidade das informações.

Para esclarecer se a Incubadora estabelece objetivos pessoais com a finalidade de mostrar para cada um dos colaboradores. Foi proposto a explicação de como os colaboradores podem contribuir para os resultados estratégicos da empresa.

Sim, isso é feito desde que foram criados os Grupos de Trabalho - GT, uma espécie de divisão do trabalho para os colaboradores. Para cada membro desses grupos é definida uma atividade (ou tarefa) como forma de deixar claro que a ação da INCEPS só trará resultados positivos se houver engajamento por parte desse membro. (Coordenador).

O Coordenador estabelece a divisão dos membros em GTs - Grupos de Trabalhos, para que os resultados estratégicos sejam melhores desenvolvidos. Pois através desse sistema, os colaboradores podem trabalhar em conjunto, desenvolvendo as atividades em equipes. Pode-se atribuir os GTs da Incubadora em comparativo com a departamentalização em uma organização. Segundo Oliveira (2002, p.114), “a departamentalização é o agrupamento", no qual os critérios específicos de homogeneidade das atividades e dos correspondentes, recursos humanos, financeiros, materiais, entre outros recursos, contribui na formação do sistema de gestão.
Para isso, a Incubadora deve conhecer e converter a estratégia em processo contínuo. Portanto, foi levantado se há alguma conexão entre o orçamento e o planejamento estratégico. E se o planejamento estratégico utiliza o Balanced Scorecard como ferramenta de analisar e traçar estratégias na construção de plano financeiro. Diante disso, o Coordenador contestou:

Sim, todo o planejamento é feito anualmente $e$ avaliado mensalmente tendo como principal elemento o orçamento disponível para a realização das atividades propostas. (Coordenador).

Segundo Kaplan e Norton (1997), as unidades de negócio vinculam seus objetivos financeiros à estratégia da empresa, o qual estabelece metas a longo prazo. Por isso o plano financeiro feito anualmente é importante para o crescimento da INCEPS, organizacionalmente e financeiramente, pois no planejamento a capacitação de recursos será bem-sucedida. Quando indagado sobre as reuniões gerencias de análise e revisão de estratégia há algum monitoramento do progresso em relação à estratégia, o coordenador diz que:

Sim. O monitoramento dos resultados é atribuição de cada grupo de trabalho. Assim, cabe ao GT de projetos e pesquisas não só elaborar os projetos para submetê-los aos agentes financiadores como também monitorar o processo de análise $e$ aprovação e, uma vez aprovado, monitorar a sua execução. $O$ mesmo vale para os outros $G T^{\prime}$ 's. (Coordenador).

Quando atribuído ao controle de análise e revisão de estratégia à Incubadora, melhor será seu desenvolvimento. Diante disso, "o controle é a função do processo administrativo que, mediante a comparação com padrões previamente estabelecidos, procura medir e avaliar o desempenho e o resultado das ações, com finalidade de realimentar os tomadores de decisões". (OLIVEIRA, 2014, p.268). Diante de tal perspectiva, surgi a seguinte questão, se a Incubadora utiliza um sistema informatizado como forma de melhorar gerenciamento e compartilhamento das informações dentro da Incubadora. 
Não, mas já está sendo planejado um sistema desse tipo com a ajuda de um estudante do curso de SI (Sistemas de Informação) do Campus do Litoral Norte, Breno Lataff, que faz parte da equipe de um projeto financiado pelo $\mathrm{CNPq}$ ora em execução pela INCEPS. (Coordenador).

Com a inexistência de um sistema informatizado, as informações podem sofrer com a dificuldade de transmitir informações entre si e para gerações posteriores na INCEPS. Diante disso, a adoção da Tecnologia da Informação nas empresas pode-se admitir hardwere, como ferramenta e domínio de dados e software para informações e pessoas, ou seja, inteligência e conhecimento. (TELLES, 2003).

Para mobilizar a mudança por meio da liderança executivo, o gestor deve ter controle sobre seu planejamento estratégico. Diante disso, como pode envolver a liderança executiva nos processos de mudança para a implementação do Planejamento estratégico. O Coordenador diz, que é:

Total e compromissada, mas de um modo geral há o problema de se concentrar as responsabilidades na liderança, mesmo aquelas que poderiam ser de outras pessoas. (Coordenador).

Mesmo sendo função do Coordenador, comprometer-se com o trabalho e a formulação das estratégias, o mesmo diz que está sobrecarregado. Porém o Coordenador deve encarar a Incubadora como sendo o gestor principal, delegando atividades para todos os GTs. Portanto, segundo Oliveira (2014, 17), "o planejamento estratégico é o processo administrativo que proporciona sustentação metodológica para se estabelecer a melhor direção a ser seguida pela empresa". Nessa circunstância, foi perguntado se a liderança executiva buscou criar equipes estratégicas, realizar reuniões coletivas com o pessoal e promover a comunicação aberta em toda a organização.

Sim. As equipes estratégicas podem ser consideradas como sendo os grupos de trabalho (GTs). Embora esses grupos tenham responsabilidades e funções específicas, os mesmos atuam sempre em conjunto e os resultados das atividades de cada um, são apresentados $e$ analisados coletivamente em reuniões mensais. (Coordenador).
O trabalho em equipe possibilita a troca de conhecimento e agilidade no cumprimento de metas e objetivos compartilhados, uma vez que otimiza o tempo de cada pessoa e ainda contribui para conhecer outros indivíduos a aprender novas tarefas. Isto está bem exposto nas palavras do Coordenador da INCEPS, quando se referia a equipe na perspectiva da multiplicação do conhecimento de diversas formas. Dando continuidade aos questionamentos foi perguntado sobre os desafios enfrentados pelos colaboradores na execução do planejamento.

São muitos, não só os desafios como as dificuldades propriamente ditas. De um modo geral, eu diria que os principais são: a extrema burocracia da UFPB, a demora no atendimento de alguma demanda da INCEPS à UFPB e a instabilidade financeira da Instituição, principalmente no que se refere à demora na liberação de recursos financeiros. (Coordenador).

A maior dificuldade enfrentada pela Incubadora de acordo com o Coordenador, é a extrema burocracia da UFPB, a qual dificulta no processo de aquisições de matérias para a INCEPS. Também os colaboradores não possuem acesso ao planejamento estratégico da incubadora. Portanto, um bom planejamento estratégico contribuirá para o aumento de controle, minimizando os riscos e mantendo todos os colaboradores a noção do desenvolvimento da Incubadora e dos empreendimentos por ela incubados.

\section{Considerações finais}

A Economia Solidária pode-se dizer que é uma das alternativas existentes aos trabalhadores ante o acirramento da questão social, gerado pela reestruturação do capitalismo no século XX e começo do século XXI. É manifestada, todavia, por grupos informais, cooperativas e associações de trabalho, entre outros, que têm como objetivo comumente a geração de trabalho e renda, bem como as inclusões sociais e econômicas desses trabalhadores (LISBOA FILHO, 2016).

Considerando o trabalho desenvolvido neste estudo, pode-se afirmar que a gestão estratégica, pode trazer diversos benefícios para as organizações que a implanta, seja em órgãos públicos ou em empresas privadas. Isso acontece devido ao fato de a gestão estratégica compor uma parte da Administração 
amplamente reconhecida pela sua capacidade de proporcionar mudanças positivas nas organizações. Através do modelo de gestão torna-se possível traçar estratégias que permitem o norteamento e gerenciamento dos objetivos estipulados a fim de atender as demandas por bens e serviços públicos de qualidade dentro dos prazos determinados e com a otimização do uso de recursos financeiros.

No que tange à pesquisa realizada junto INCEPS Incubadora de Empreendimentos Populares solidários, Campus III, Bananeiras - PB, foi possível compreender o grau limitado do Coordenador sobre o planejamento estratégico, ao mesmo tempo em que se verificou o pouco conhecimento na elaboração e gestão do mesmo. Outro fato que deve ser relatado é quanto às informações e aos problemas existentes envolvendo ao planejamento, percebeu-se que essas informações são limitantes para uma boa compreensão, pois os colaboradores não estão inteiramente do planejamento da Incubadora.

A pesquisa ainda permitiu identificar dificuldades encontradas no processo de elaboração do Planejamento Estratégico. de forma sucinta, pode-se dizer que os fatores que causam a maioria dos problemas nas estratégias da INCEPS são: grande dependência de terceiros, falta de recursos humanos capacitados para trabalhar com projetos, pesquisa, capacitação e gestão, falta de comprometimento de algumas pessoas envolvidas, falta de agilidade e próatividade, falta de experiência dos alunos bolsista e voluntários, falta de apoio dos níveis hierárquicos superiores da instituição de ensino da UFPB, falta dos planos de ações, comprometendo assim o planejamento da Incubadora.

Sabendo da importância que o planejamento estratégico tem dentro das Incubadoras e quando mal elaborado e/ou gerenciados pode levar as organizações ao fracasso, sugere-se à INCEPS, reavaliar a forma como o planejamento é elaborado e gerenciado, avaliando inclusive a percepção dos membros internos à organização que estão envolvidos com os projetos. Pois, como se sabe não existe uma única forma de gerenciar estrategicamente, sobretudo pela complexidade que estes possuem, pois, as estratégias dificilmente se iniciam e terminam exatamente como o planejado; falhas e desvios que diversas vezes são decorrentes de obstáculos externos, fora do controle da incubadora, podem ser moderados ou até mesmo evitados com um gerenciamento de estratégias eficaz.
Portanto, é importante considerar que cada organização deve definir sua estratégia de atuação, no caso do presente trabalho o planejamento estratégico deva ter a participação de todos os colaboradores ou pelo menos os que compõe o GT de Gestão da INCEPS. É importante que a Incubadora além de um processo bem estruturado tenha conhecimento sobre todas as fases do planejamento estratégico, pois somente dessa forma, poderá focalizar nos resultados e comprovar a eficiência destes.

Os resultados acima apresentados podem revelar análise restrita em função do número dos sujeitos avaliados, isto é, de apenas um coordenador. Isto dito, representa a realidade organizacional local. Entretanto, esta visão do presente estudo deve referenciar, particularmente, pesquisas futuras no contexto apresentado.

\section{Agradecimento}

A todos que fazem parte da Equipe INCEPS, em especial ao Coordenador Prof. Dr. Genyson Evangelista pelo belíssimo trabalho à frente da ITCP do Campus III da UFPB.

\section{Referências}

ARROYO, J. C. T.; SCHUCH, F. C. Economia popular e solidária. São Paulo: Perseu Abramo, 2006. p. 21.

ATLAS da economia solidária no Brasil 2005. Brasília: MTE, SENAES, 2006.

CAUlliRAUX, H. M. Modelo de Gestão para Incubadoras de Empresas: uma estrutura de indicadores de desempenho. Rede de Incubadoras do rio de Janeiro, E-Pepers Serviços Editoriais Ltda, 2001. P.96.

CERTO, Samuel C.; PETER, J. P. Administração estratégica: planejamento e implantação de estratégias. Trad. Reynaldo C. Marcondes, Ana Maria R. Cesar. 3 ed. São Paulo: Pearson Education do Brasil, 2010.

COELHO JUNIOR, F. A. Gestão estratégica: um estudo de caso de percepção de mudança de cultura organizacional. Psico-USF (Impr.) [Online]. 2003, vol.8, n.1, pp. 81-89. ISSN 14138271. 
DORNELAS, J. C. A. PLANEJANDO INCUBADORAS DE EMPRESAS: COMO desenvolver um plano de negócios para incubadoras. Rio de janeiro: Campus, 2002.

FERREIRA, M. P. et al. Gestão por indicadores de desempenho: resultados na incubadora empresarial tecnológica. Produção, v. 18, n. 2, maio/ago. 2008, p. 302-318.

GIL, A. C. Métodos e técnicas de pesquisa social. São Paulo: Atlas, 2008.

HITT, M. A. IRELAND, R. D. HOSHISSON, R. E. Administração Estratégica: Competitividade e globalização. - 2. ed. - São Paulo: Cengage Learning, 2012.

KAPLAN, R. e NORTON, D. P. A Estratégia em Ação: Balanced Scorecard; tradução Luiz Euclides Trindade Frazão filho. - Rio de Janeiro: Elsevier, 1997, 20ª Reimpressão.

LAKATOS, E. M.; MARCONI, M. de. Fundamentos de metodologia científica. 6. ed. 5. reimp. São Paulo: Atlas, 2007.

LISBOA FILHO, Flavi Ferreira et al. Identidade e incubação: processos coletivos de trabalho e o caso da Incubadora Social da Universidade Federal de Santa Maria. Revista de Gestão e Organizações Cooperativas, v. 3, n. 5, 2016.

MARTINS, H. F.; MARINI, C. Um guia de governança para resultados na administração pública. Publix Editora, 2010.

OLIVEIRA, D. P. R. PLANEJAMENTO ESTRATÉGICO: conceito, metodologia e práticas. - 32. ed. - São Paulo: Atlas, 2014.

OLIVEIRA, D. P. R. Sistemas, organização e métodos: uma abordagem gerencial. -14 . ed. São Paulo: Atlas, 2002.

RAUPP, F. M e BEUREN, I. M. PERFIL DO SUPORTE OFERECIDO PELAS INCUBADORAS BRASILEIRAS ÀS EMPRESAS INCUBADAS. REAd - Edição 69 Vol. 17 - $\mathrm{N}^{\circ} 2$ - maio/agosto 2011 - p. 330-359.
RIBEIRO, S. A.; ANDRADE, R. M. G. de e ZAMBALDE, A. L. Incubadoras de empresas, inovação tecnológica e ação governamental: o caso de Santa Rita do Sapucaí (MG). Cad. EBAPE.BR [online]. 2005, vol.3, n.spe, pp. 01-14. ISSN 16793951.

SILVA, F. M. G. ANDRADE JÚNIOR, P. P. INCUBADORAS DE EMPRESAS E O DESENVOLVIMENTO ECONÔMICO E TECNOLÓGICO. RET - Revista de Engenharia e Tecnologia. V. 4, n. 3, Dez/2012. ISSN 21767270 .

SINGER, P. Introdução à Economia Solidária. São Paulo: Perseu Abramo, 2002.

SPERANCINI, J. H. B. S. et al. AVALIAÇÃO DO APOIO À INOVAÇÃO EM INCUBADDORAS PAULISTAS. RDE - REVISTA DE DESENVOLVIMENTO ECONÔMICO. Salvador, BA. Ano XV No 28, dezembro de 2013.

TAVARES, M. C. Gestão Estratégica. - 3. ed. - São Paulo: Alas, 2010.

TEIXEIRA, G. M.; SILVEIRA, A. C. da; BASTOS NETO, C. P. dos S.; OLIVEIRA, G. A. de. Gestão estratégica de pessoas. 2 ed. Rio de Janeiro: Editora FGV, 2010.

TELLES, R. Marketing empresarial. São Paulo: Saraiva, 2003. ISBN 85-02-03814-1.

VERGARA, S. C. Projeto e relatório de pesquisa em administração. São Paulo: Atlas, 2006.

ZANCO, Alcidir Mazutti. Gestão do Conhecimento nas Cooperativas. Revista de Gestão e Organizações Cooperativas, v. 3, n. 5, 2016.1llf

ZOUAIN, D. M. e SILVEIRA, A. C. da. Aspectos estratégicos do modelo de gestão em incubadoras de empresas de base tecnológica. Cad. EBAPE.BR [online]. 2006, vol.4, n.3, pp. 01-14. ISSN 1679-3951. 